\title{
Determination of the Critical Stress Associated with Dynamic Phase Transformation in Steels by Means of Free Energy Method
}

\author{
Clodualdo Aranas Jr. ${ }^{1, *}$, Samuel Rodrigues ${ }^{2,3}$, Ameth Fall ${ }^{4}$, Mohammad Jahazi ${ }^{4}$ and \\ John Jonas ${ }^{3}$ \\ 1 Mechanical Engineering, University of New Brunswick, Fredericton, NB E3B 5A3, Canada \\ 2 Federal Institute of Education, Science and Technology of Maranhao, Sao Luis 65075-441, Maranhao, Brazil; \\ samuel.rodrigues@mail.mcgill.ca \\ 3 Materials Engineering, McGill University, Montreal, QC H3A 0C5, Canada; john.jonas@mcgill.ca \\ 4 Département de Génie Mécanique, École de Technologie Supérieure, Montreal, QC H3C 1K3, Canada; \\ amethmaloum@gmail.com (A.F.); mohammad.jahazi@etsmtl.ca (M.J.) \\ * Correspondence: clodualdo.aranas@mail.mcgill.ca; Tel.: +1-514-862-7983
}

Received: 30 April 2018; Accepted: 14 May 2018; Published: 16 May 2018

\begin{abstract}
The double differentiation method overestimates the critical stress associated with the initiation of dynamic transformation (DT) because significant amounts of the dynamic phase must be present in order for its effect on the work hardening rate to be detectable. In this work, an alternative method (referred to here as the free energy method) is presented based on the thermodynamic condition that the driving force is equal to the total energy obstacle during the exact moment of transformation. The driving force is defined as the difference between the DT critical stress (measured in the single-phase austenite region) and the yield stress of the fresh ferrite that takes its place. On the other hand, the energy obstacle consists of the free energy difference between austenite and ferrite, and the work of shear accommodation and dilatation associated with the phase transformation. Here, the DT critical stresses in a C-Mn steel were calculated using the free energy method at temperatures ranging from $870{ }^{\circ} \mathrm{C}$ to $1070{ }^{\circ} \mathrm{C}$. The results show that the calculated critical stress using the present approach appears to be more accurate than the values measured by the double differentiation method.
\end{abstract}

Keywords: dynamic transformation; free energy method; critical stress; DT ferrite

\section{Introduction}

The application of the double differentiation method [1] on a stress-strain curve obtained from steel deformed at elevated temperatures has been proven to provide information regarding the initiation of various dynamic metallurgical softening phenomena such as twinning, recrystallization and recovery [2,3]. More recently, it has been proven by the present authors that this approach can also identify the onset of dynamic transformation (DT) of austenite to ferrite during hot compression and rolling [4-6]. Numerous researchers have shown that austenite can transform into ferrite by deformation at high temperature [7-12]. In the process of double differentiation, the stress-strain curve is initially fitted with a polynomial function, then the strain hardening rate $(\theta)$ is determined using the relation:

$$
\theta=\left(\frac{\delta \sigma}{\delta \varepsilon}\right)_{\dot{\varepsilon}}
$$

where the stress $(\sigma)$ and strain $(\varepsilon)$ are obtained at a fixed strain rate $(\dot{\varepsilon})$. 
The inflection points in the plot of strain hardening rate versus stress $(\theta-\sigma)$ provide the initiation points of each dynamic softening mechanism. These points are clearly identified by the condition:

$$
\left(\frac{\delta \theta}{\delta \sigma}\right)=0
$$

The minima of the $-\delta \theta / \delta \sigma$ versus the applied stress detect the onset of the softening mechanisms. In a previous work [12], two softening mechanisms have been identified during deformation of C-Mn steels at temperatures above the $\mathrm{Ae}_{3}$ (the equilibrium transformation temperature between the two-phase austenite and ferrite, and the single-phase austenite), which are associated with the occurrence of both dynamic transformation and dynamic recrystallization (DRX). Moreover, it has been proven that the former takes place at a lower strain than the latter by means of microstructural analysis.

Although the double differentiation method is designed to track the initiation points of various dynamic softening phenomena, there is no proof that the calculated critical strains (or stresses) are indeed the exact onset of the metallurgical phenomenon. It is therefore safe to assume that this method is purely mathematical in nature and the results should always be complemented with microstructures. Moreover, this approach highly depends on the changes in the strain hardening rate during loading. In the case of DT, the strain hardening can only be significantly affected if there is approximately $5-10 \%$ volume fraction of the dynamically transformed phase [13]. Therefore, the critical strain (and stress) using this method is always higher than the actual initiation point. This was also discussed by the present authors in a previous paper [14], however, this work was focused in the occurrence of dynamic transformation in pure titanium. The present work will provide an alternative approach to calculate the critical stress in steels by using the free energy difference between the phases and the yield stress of freshly formed ferrite at elevated temperature.

\section{Materials and Methods}

The present analysis is focused on a steel with $0.06 \mathrm{wt} \% \mathrm{C}, 0.3 \mathrm{wt} \% \mathrm{Mn}$ and $0.01 \mathrm{wt} \% \mathrm{Si}$ with a paraequilibrium $\mathrm{Ae}_{3}$ temperature of $870{ }^{\circ} \mathrm{C}$. Note that this is similar to the material used in previous investigations by the present authors [4,6,12,15-17]. Hot compression tests were performed on a $100 \mathrm{kN}$ MTS machine (MTS, Eden Prairie, MN, USA) equipped with a radiation furnace and a temperature controller. Cylindrical samples with diameters of $6 \mathrm{~mm}$ and heights of $9 \mathrm{~mm}$ were machined from hot-rolled plates with the longitudinal axis parallel to the rolling direction. Samples were heated from room temperature going to deformation temperature at a rate of $1^{\circ} \mathrm{C} / \mathrm{s}$. Then, the samples were held for $10 \mathrm{~min}$ before deforming to a strain of 0.7 and strain rate of $1 \mathrm{~s}^{-1}$ followed by water quenching. The deformation was carried out at temperatures ranging from $500{ }^{\circ} \mathrm{C}$ to $750{ }^{\circ} \mathrm{C}$ to estimate the yield stress of single-phase ferrite and at temperatures ranging from $900{ }^{\circ} \mathrm{C}$ to $1000{ }^{\circ} \mathrm{C}$ to determine the DT critical stress in the single-phase austenite region. These values, including the microstructures were reported in an earlier work [12,15].

The compressed samples were sectioned containing the longitudinal axis. These were then mounted using a conductive hot mounting epoxy followed by rough polishing using 400, 600, 800 and 1200 grit SiC papers. The final polishing was performed using $1 \mu \mathrm{m}$ and $3 \mu \mathrm{m}$ diamond suspensions. The polished samples were etched using $2 \%$ nital solution followed by $10 \%$ aqueous metabisulfite solution to improve the contrast. The optical microstructures were taken using the Nikon optical microscope linked with Clemex system. The volume fraction of DT ferrite was calculated using the ImageJ software (Version 1.38e, National Institutes of Health, Bathesda, MD, USA). 


\section{Results and Discussion}

Examples of optical microstructures of the samples deformed to a strain of 0.7 at a temperature range of $900-960{ }^{\circ} \mathrm{C}\left(30-90^{\circ} \mathrm{C}\right.$ above its $\left.\mathrm{Ae}_{3}\right)$ and a strain rate of $1 \mathrm{~s}^{-1}$ are displayed in Figure 1. These samples were quenched immediately after deformation. The light area is ferrite while the dark area is martensite (previously austenite). Since these samples are deformed above the $\mathrm{Ae}_{3}$, it is expected that the microstructure will be completely martensite after quenching. However, significant amounts of dynamically formed ferrite are present and its volume fraction is decreasing with temperature. There is approximately $60 \%, 50 \%$ and $40 \%$ of DT ferrite at deformation temperatures of $900{ }^{\circ} \mathrm{C}$ (Figure 1a), $930{ }^{\circ} \mathrm{C}$ (Figure $1 \mathrm{~b}$ ) and $960{ }^{\circ} \mathrm{C}$ (Figure 1c), respectively. The DT ferrite tends to re-transform back into the more thermodynamically stable austenite upon isothermal holding $[17,18]$.
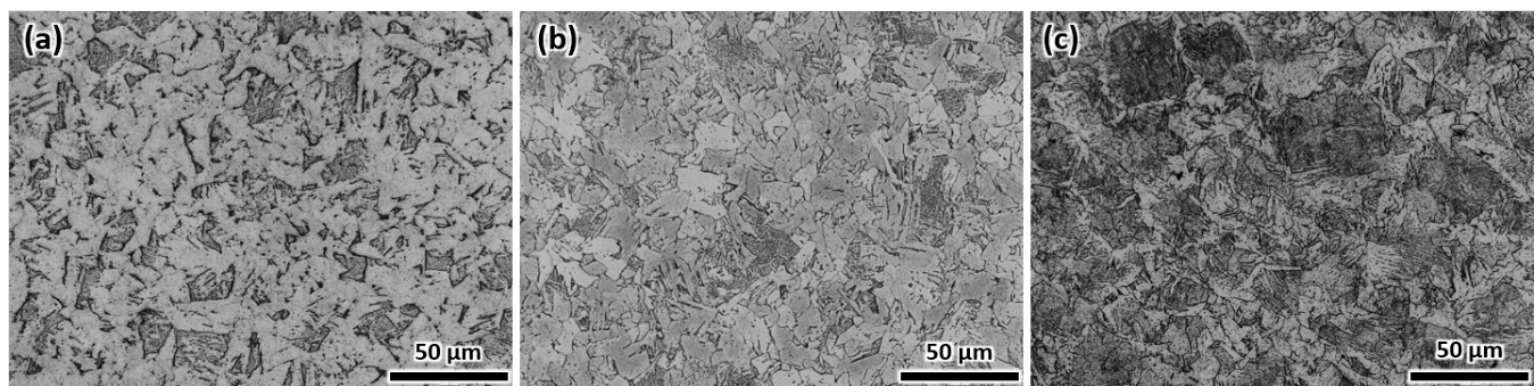

Figure 1. The optical microstructures obtained from the samples deformed to a strain of 0.7 at a strain rate of $1 \mathrm{~s}^{-1}$ and deformation temperatures of (a) $900{ }^{\circ} \mathrm{C}$; (b) $930{ }^{\circ} \mathrm{C}$ and (c) $960{ }^{\circ} \mathrm{C}$. The samples were water quenched immediately after deformation.

The driving force for transformation $\left(E_{D F}\right)$ is the flow stress difference between the DT critical stress $\left(\sigma_{\mathcal{c}-\gamma}\right)$ and the yield stress of the fresh ferrite $\left(\sigma_{Y S-\alpha}\right)$ that takes its place. This is defined by the equation:

$$
E_{D F}=\sigma_{C-\gamma}-\sigma_{Y S-\alpha}
$$

On the other hand, the total energy obstacle $\left(E_{B}\right)$ consists of the free energy difference between the austenite and ferrite $\left(\Delta G_{\gamma-\alpha}\right)$, and the work of shear accommodation $\left(W_{S A}\right)$ and dilatation $\left(W_{D}\right)$ associated with the phase change. Therefore, the total energy obstacle is described by the following relation:

$$
E_{B}=\Delta \mathrm{G}_{\gamma-\alpha}+W_{S A}+W_{D}
$$

The free energy difference between the phases can be conveniently calculated using thermodynamic software such as FactSage, MatCalc and ThermoCalc. The required shear work to transform austenite to ferrite is estimated to be 0.22 [19]. Since the transformation should initially take place in the most favorably oriented grain with respect to the applied stress (Schmid factor, $m=0.5$ ), which can alternatively be identified by means of the double differentiation method, the amount of shear work at the critical stress $\left(\sigma_{C-\gamma}\right)$ is defined as:

$$
W_{S A}=\sigma_{C-\gamma} \times 0.5 \times 0.22
$$

The transformation from austenite to a less dense ferrite requires a dilatation of about 3\% [19]. Therefore, the dilatation work is given by the following equation:

$$
W_{D}=\sigma_{C-\gamma} \times \sqrt{ } m \times 0.03
$$

The orientation factor $(\sqrt{ } m)$ is based on the most orientated grain, which is 0.707 . 
Thermodynamically, the dynamic transformation will only start to occur when the driving force is exactly equal to its energy obstacle. This condition can be expressed as:

$$
E_{D F}=E_{B}
$$

By substituting the equations for driving force and energy obstacles stated above, the following equation can be obtained:

$$
\sigma_{C-\gamma}-\sigma_{Y S-\alpha}=\Delta \mathrm{G}_{\gamma-\alpha}+\left(\sigma_{C-\gamma} \times 0.5 \times 0.22\right)+\left(\sigma_{C-\gamma} \times 0.707 \times 0.03\right)
$$

By using Equation (8), the dependence of the critical stress on the free energy difference between austenite and ferrite, and the yield stress of ferrite can be described by the equation:

$$
\sigma_{C-\gamma}=\frac{\Delta G_{\gamma-\alpha}+\sigma_{Y S-\alpha}}{[1-(0.5)(0.22)-(0.707)(0.03)]}
$$

To determine the critical stress associated with DT, the free energy difference between the phases $\left(\Delta G_{\gamma-\alpha}\right)$ was calculated using the FactSage thermodynamic software employing FSstel database [20]. This is shown in Figure 2 for temperatures of up to $200{ }^{\circ} \mathrm{C}$ above the $\mathrm{Ae}_{3}$ with a temperature increment of $20^{\circ} \mathrm{C}$. The maximum free energy difference is around $90 \mathrm{~J} / \mathrm{mol}$ at $1070{ }^{\circ} \mathrm{C}$, a temperature midway between the $\mathrm{Ae}_{3}$ and the formation of high temperature ferrite. This free energy value is expected to decrease progressively with further increase in temperature as it approaches the delta ferrite formation temperature [4].

Since the yield stress of ferrite cannot be obtained experimentally at temperatures above the $\mathrm{Ae}_{3}$, it was taken here by means of extrapolation from the values measured in the single-phase ferrite region [15]. At least three measurements were performed to ensure accuracy. These values are shown in Figure 3 (see solid line with square markers). The yield stress of ferrite is around $46 \mathrm{MPa}$ and $27 \mathrm{MPa}$ at temperatures $870{ }^{\circ} \mathrm{C}$ and $1070{ }^{\circ} \mathrm{C}$, respectively. This is approximately $1 \mathrm{MPa}$ decrease in yield stress per $10^{\circ} \mathrm{C}$ of increase in temperature. However, since the formation of ferrite is characterized by the initial formation of Widmanstätten ferrite, the yield stress of the latter is more suitable for the present analysis. Furthermore, since it is difficult to measure the actual yield stress of Widmanstätten ferrite, an estimation of yield stress was made by means of hardness measurement [16], which is $18 \%$ higher than that of the polygonal ferrite. The dependence of the estimated yield stress of Widmanstätten ferrite on temperature is shown in Figure 3 (see broken lines with triangle markers).

The data of Figures 2 and 3 were taken and the critical stresses were calculated using Equation (9) above. For reference, a conversion factor of $1 \mathrm{MPa}=7.2 \mathrm{~J} / \mathrm{mol}$ was employed [16,19]. The result is displayed in Figure 4 (see red broken lines with triangle markers). Here the critical stresses are approximately $63 \mathrm{MPa}$ at a temperature between $870{ }^{\circ} \mathrm{C}$ and $950{ }^{\circ} \mathrm{C}$. Then, it slightly decreases with increasing temperature at a rate of around 0.8 per $10^{\circ} \mathrm{C}$. It registered a decrease of about $10 \mathrm{MPa}$ at the highest temperature of $1070{ }^{\circ} \mathrm{C}$.

The calculated critical stresses by means of the free energy method are considerably lower than that of the values obtained from the double differentiation method in the literature for the same material [15], see solid black line with square markers. Although the trend appears to be similar, the values have a difference of around 30 to $40 \mathrm{MPa}$. It is important to note that the critical stresses obtained using the free energy method are associated with the formation of Widmanstätten ferrite plates, which has the tendency to coalesce into polygonal grains upon continued deformation because of its near-identical orientation [21]. These plates are known to nucleate at a relatively lower strain [21]. 


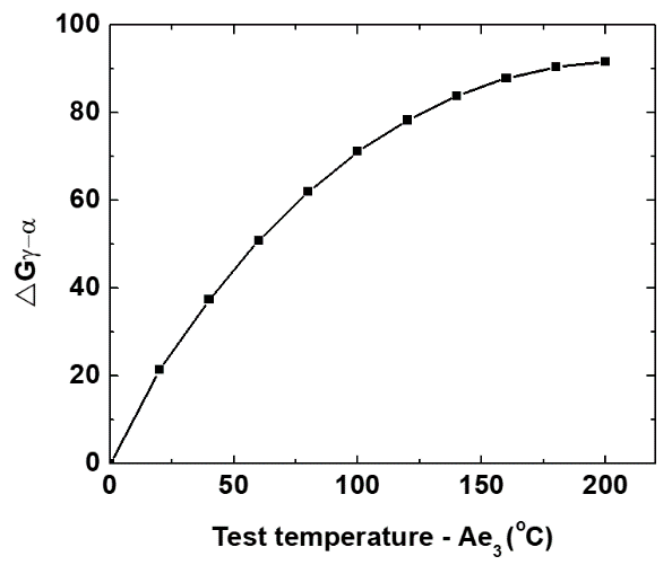

Figure 2. The free energy difference between the austenite and ferrite calculated using the FactSage thermodynamic software employing FSstel database. Note that the starting temperature is the $\mathrm{Ae}_{3}$.

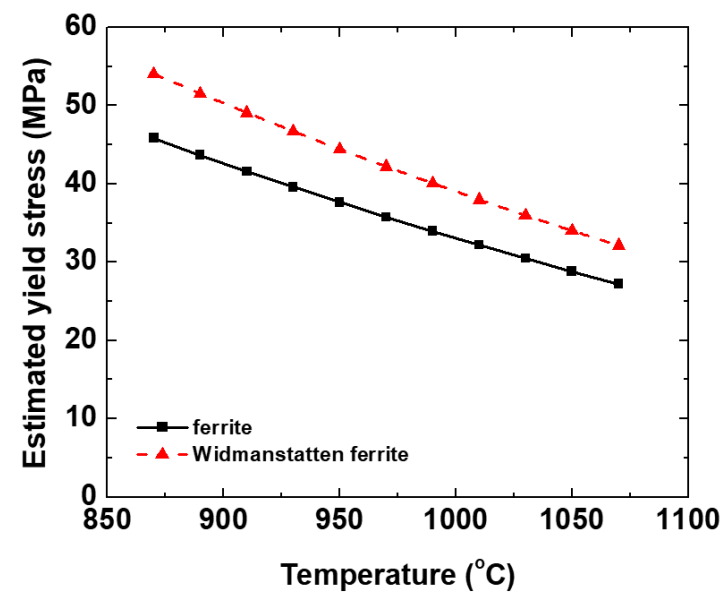

Figure 3. The estimated yield stress of ferrite at temperatures above the $\mathrm{Ae}_{3}$ obtained from extrapolation using the data from the compression tests performed in the single-phase ferrite region. The yield stress of Widmanstätten ferrite is estimated to be $18 \%$ higher than that of the polygonal ferrite.

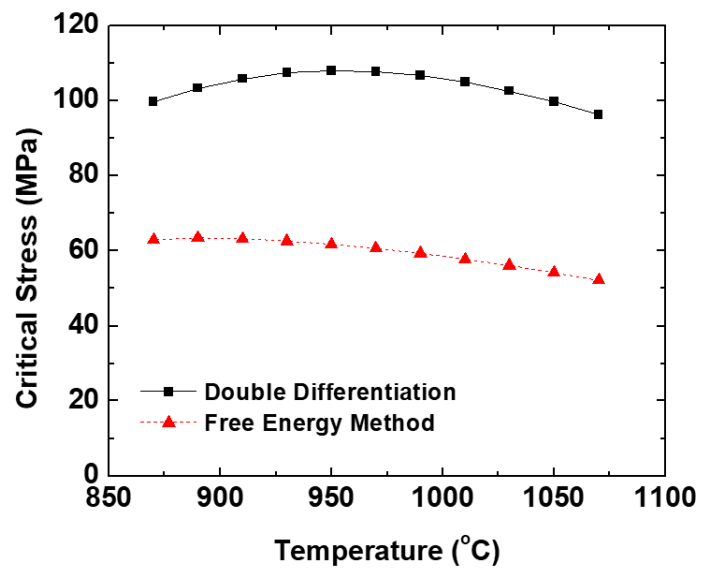

Figure 4. The calculated critical stresses using the free energy method (broken line) and the double differentiation method (solid line).

The double differentiation method relies on substantial softening of the material, which requires a significant volume fraction of DT ferrite (at least around 5\%) for it to become detectable. Therefore, 
the double differentiation overestimates the onset of DT. It is also safe to assume that the exact initiation of DT can only be identified using the free energy method. Furthermore, it is difficult to relate the critical stress to the volume fraction of DT ferrite as the former is associated with nucleation (thermodynamics) while the latter is associated with growth (kinetics).

The required work for shear displacements and dilatation during DT were calculated using the critical stresses obtained from the present approach as displayed in Figure 5a,b, respectively. In Figure 5a, the required shear accommodation work is in the range $45-55 \mathrm{~J} / \mathrm{mol}$. This is significantly lower than the values obtained from the double differentiation method which is in the range 120-130 J/mol. Similarly, in Figure 5b, the required dilatation work obtained from the present method is in the range 1-2 J/mol whereas the double differentiation method requires $14-17 \mathrm{~J} / \mathrm{mol}$ of work. As discussed above, this discrepancy is based on the overestimated values of critical stresses obtained from the double differentiation method. The calculation of critical stress using the free energy method can potentially be employed in the modelling of thermomechanical processing to account for the occurrence of dynamic phase transformation.
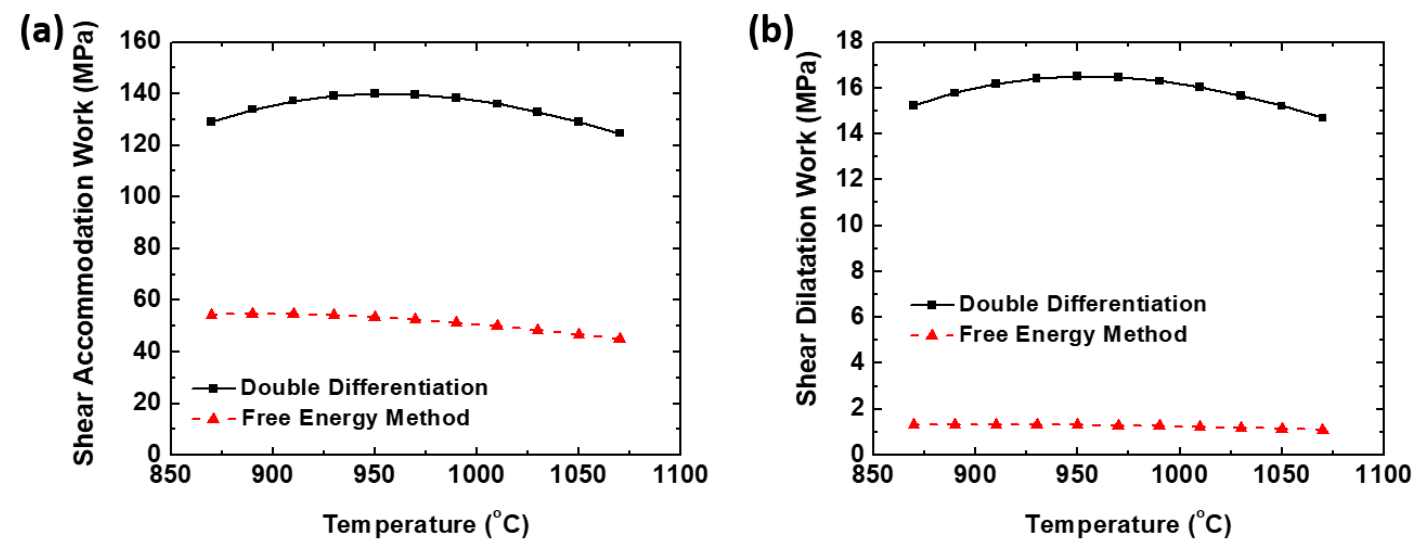

Figure 5. The calculated (a) shear accommodation and (b) dilatation work based on the critical stresses of Figure 4.

\section{Conclusions}

1. An alternative method is proposed to calculate the critical stress for dynamic transformation in steels by using the free energy difference between the austenite and ferrite, and the yield stress of the freshly formed ferrite, referred to here as the free energy method. A simple equation was generated for this purpose by assuming that the driving force is equal to that of the energy obstacle at the exact initiation point of dynamic transformation.

2. The critical stress obtained from the free energy method is always lower than that of the values calculated using the double differentiation method. The latter overestimates the critical stress as it requires a substantial volume fraction of softening for it to be detectable.

3. The present approach can potentially be used to model the occurrence of dynamic transformation above the $\mathrm{Ae}_{3}$ during thermomechanical processing without performing hot deformation experiments.

Author Contributions: All the authors contributed to this research work. Conceptualization, C.A., J.J. and M.J.; Data curation, C.A., S.R. and A.F.; Formal analysis, C.A., S.R. and A.F.; Funding acquisition, J.J. and M.J.; Investigation, C.A.; Methodology, S.R. and A.F.; Software, S.R. and A.F.; Supervision, J.J. and M.J.; Validation, C.A., J.J. and M.J.; Writing—original draft, C.A.; Writing—review \& editing, J.J. and M.J.

Acknowledgments: The authors acknowledge with gratitude funding received from the McGill Engineering Doctoral Award (MEDA) program, the Industrial Research Chair in Forming Technologies of High Strength Materials of the École de Technologie Supérieure of Montréal, the Natural Sciences and Engineering Research 
Council of Canada, the Brazilian National Council for Scientific and Technological Development (CNPq Brazil) and the New Brunswick Innovation Fund.

Conflicts of Interest: The authors declare no conflict of interest.

\section{References}

1. Poliak, E.; Jonas, J.J. A one-parameter approach to determining the critical conditions for the initiation of dynamic recrystallization. Acta Mater. 1996, 44, 127-136. [CrossRef]

2. Mirzadeh, H.; Najafizadeh, A. Prediction of the critical conditions for initiation of dynamic recrystallization. Mater. Des. 2010, 31, 1174-1179. [CrossRef]

3. Momeni, A.; Dehghani, K.; Ebrahimi, G.R. Modeling the initiation of dynamic recrystallization using a dynamic recovery model. J. Alloys Compd. 2011, 509, 9387-9393. [CrossRef]

4. Grewal, R.; Aranas, C.; Chadha, K.; Shahriari, D.; Jahazi, M.; Jonas, J.J. Formation of Widmastatten ferrite at very high temperatures in the austenite phase field. Acta Mater. 2016, 109, 23-31. [CrossRef]

5. Rodrigues, S.F.; Aranas, C.; Wang, T.; Jonas, J.J. Dynamic transformation of an X70 steel under plate rolling conditions. ISIJ Int. 2017, 57, 162-169. [CrossRef]

6. Jonas, J.J.; Aranas, C.; Basabe, V.V.; Ghosh, C. Dynamic transformation during the torsion simulation of strip rolling. Mater. Sci. Forum 2014, 783, 39-44. [CrossRef]

7. Beladi, H.; Kelly, G.L.; Shokouchi, A.; Hodgson, P.D. The evolution of ultrafine ferrite formation through dynamic strain-induced transformation. Mater. Sci. Eng. A 2004, 371, 343-352. [CrossRef]

8. Yang, Z.; Wang, R. Formation of ultra-fine grain structure of plain low carbon steel through deformation induced ferrite transformation. ISIJ Int. 2003, 43, 761-766. [CrossRef]

9. Xiong, Z.P.; Saleh, A.A.; Kostryzhev, A.G.; Pereloma, E.V. Strain-induced ferrite formation and its effect on mechanical properties of a dual phase steel produced using laboratory simulated strip casting. J. Alloys Compd. 2017, 721, 291-306. [CrossRef]

10. Zhao, L.; Park, N.; Tian, Y.; Shibata, A.; Tsuji, N. Combination of dynamic transformation and dynamic recrystallization for realizing ultrafine-grained steels with superior mechanical properties. Sci. Rep. 2016, 6, 39127. [CrossRef] [PubMed]

11. Park, N.; Shibata, A.; Terada, D.; Tsuji, N. Flow stress analysis for determining the critical condition of dynamic ferrite transformation in 6Ni-0.1C steel. Acta Mater. 2013, 61, 163-173. [CrossRef]

12. Aranas, C.; Shen, Y.J.; Rodrigues, S.F.; Jonas, J.J. Microstructural evolution of a C-Mn steel during hot compression above the $\mathrm{Ae}_{3}$. Metall. Mater. Trans. A 2016, 47, 4357-4361. [CrossRef]

13. Ghosh, C.; Basabe, V.V.; Jonas, J.J.; Kim, Y.M.; Jung, I.H.; Yue, S. The dynamic transformation of deformed austenite at temperatures above the $\mathrm{Ae}_{3}$. Acta Mater. 2013, 61, 2348-2363. [CrossRef]

14. Aranas, C.; Foul, A.; Guo, B.; Fall, A.; Jahazi, M.; Jonas, J.J. Determination of the critical stress for the initiation of dynamic transformation in commercially pure titanium. Scr. Mater. 2017, 133, 83-85. [CrossRef]

15. Aranas, C.; Jung, I.H.; Yue, S.; Rodrigues, S.F.; Jonas, J.J. A metastable phase diagram for the dynamic transformation of austenite at temperatures above the Ae 3 . Int. J. Mater. Res. 2016, 107, 881-886. [CrossRef]

16. Aranas, C.; Jonas, J.J. Effect of $\mathrm{Mn}$ and $\mathrm{Si}$ on the dynamic transformation of austenite above the $\mathrm{Ae}_{3}$ temperature. Acta Mater. 2015, 82, 1-10. [CrossRef]

17. Aranas, C.; Rodrigues, S.F.; Shen, Y.J.; Zhang, Z.; Jonas, J.J. Time-Temperature-Reverse Transformation behaviors of a C-Mn and a $\mathrm{Nb}$ microalloyed steel after dynamic transformation above the $\mathrm{Ae}_{3}$. Steel Res. Int. 2017, 88, 1700006. [CrossRef]

18. Rodrigues, S.F.; Aranas, C.; Jonas, J.J. Retransformation behavior of dynamically transformed ferrite during the simulated plate rolling of a low $\mathrm{C}$ and an X70 Nb steel. ISIJ Int. 2017, 57, 929-936. [CrossRef]

19. Ghosh, C.; Aranas, C.; Jonas, J.J. Dynamic transformation of deformed austenite at temperatures above the $\mathrm{Ae}_{3}$. Prog. Mater. Sci. 2016, 82, 151-233. [CrossRef] 
20. Bale, C.W.; Belisle, E.; Chartrand, P.; Decterov, S.A.; Eriksson, G.; Hack, K.; Jung, I.H.; Kang, Y.Y.; Melancon, J.; Pelton, A.D.; et al. FactSage thermochemical software and databases-Recent developments. Calphad 2009, 33, 295-311. [CrossRef]

21. Basabe, V.V.; Jonas, J.J.; Ghosh, C. Formation of Widmastätten ferrite in a $0.036 \% \mathrm{Nb}$ low carbon steel at temperatures above the $\mathrm{Ae}_{3}$. Steel Res. Int. 2013, 85, 8-15. [CrossRef] 